Mind the gap: Capturing value from basic research boundary crossing inventors and partnerships

Bruno Cassiman, Reinhilde Veugelers and Sam Arts

DEPARTMENT OF MANAGERIAL ECONOMICS, STRATEGY AND INNOVATION (MSI) 


\title{
Mind the Gap: Capturing Value from Basic Research Boundary Crossing Inventors and Partnerships*
}

\author{
Bruno Cassiman \\ IESE Business School, KU Leuven and CEPR \\ bcassiman@iese.edu \\ Reinhilde Veugelers \\ KU Leuven, Bruegel and CEPR \\ reinhilde.veugelers@kuleuven.be \\ Sam Arts \\ KU Leuven and FWO \\ sam.arts@kuleuven.be
}

October 2012

First Version: October 2009

We study the process of how firms access basic research and translate this into applied research.

Drawing on basic research firms develop higher quality technologies and develop these technologies

more intensely internally. Critical in this process are boundary crossing inventors - inventors that

access basic research by active involvement in basic research projects and subsequent involvement in

the development of more applied technologies. Nevertheless, these boundary crossing inventors need

to be embedded in a complementary institutional relation between the firm and the organization

developing the basic research to have an effect. We examine this process through IMEC, an important

basic research organization in nano-electronics, with the explicit mission to bridge the gap between

basic research done at universities and applied research developed by industry.

Key words: basic research, inventor, partnership, patents, industry-science links

\footnotetext{
* The authors wish to thank Ajay Agrawal, Massimo Colombo, Dirk Czarnitzki, Lee Fleming, Alfonso Gambardella, Rahul Kapoor, Andy King, Lori Rosenkopf, Jasjit Singh, Jason Snyder, Marco Tortoriello, Giovanni Valentini, Bruno Van Pottelsberghe, Rosemarie and Arvids Ziedonis and the seminar participants at HBS, Wharton, Michigan, Toronto, UCLA, USC, Bocconi, Politecnico di Milano, LMU Munich, HEC Paris, INSEAD, University of Zurich; the MOVE, Alma Graduate School Bologna, ZEW, EARIE, EPIP, ICMIT and REER conferences for useful comments; Andre Clerix, Johan Van Helleputte and IMEC for the collaboration and data. Best Paper Award received at the $6^{\text {th }}$ IEEA-ICMIT 2012 Conference. Bruno Cassiman is a research fellow of the SP-SP Research Center at IESE Business School and acknowledges partial financial support from the Spanish Ministry of Science and Innovation through project $n^{\circ}$ ECO2009-13169, the Catalan Government Grant $n^{\circ}$ 2009-SGR919 and Fundación Ramon Areces. Financial support of the Science Foundation Flanders (FWO) and the Research Council of KULeuven is gratefully acknowledged (GOA/12/003, G.0825.12). We are also grateful to ECOOM (Policy Research Center for R\&D Monitoring) for providing us access to the patent data.
} 


\section{Introduction}

Concern has been mounting about a widening gap between basic research and applied research (Butler 2008). At the same time, little is known about the actual processes of how firms access and translate basic research into applied research. Basic research is experimental or theoretical work undertaken primarily to acquire new knowledge of the underlying foundations of phenomena and observable facts, without any particular application or use in view (OECD, Frascati Manual 2002). At the macro level basic research stimulates technological progress and ultimately economic growth (Stephan 1996). Empirical evidence at the micro level reinforces the idea that basic research is important for industrial innovation activities (Mansfield 1995 and 1998, Cohen et al 2002). Firms increasingly recognize the importance of rapid and privileged access to new scientific insights, especially in life sciences and ICT (Cockburn and Henderson 2000, Zucker et al. 1998).

In this paper we examine how firms access basic research and how this access can have an important impact on these firms' applied research. Access to basic research is complicated because basic research and applied research are typically developed in distinct institutional settings based on conflicting logics. The former is associated with science institutes like universities and public research organizations, while the latter corresponds to commercial firms (Gittelman and Kogut 2003). Therefore, companies looking to access basic research need to bridge this institutional "gap” between scientific and technology communities before basic research can be translated and developed into new technologies. In addition, bridging this institutional gap to access basic research is challenging because knowledge about early stage technologies is mostly tacit in nature and, hence, harder to transfer (Bessen 2011).

Two mechanisms for bridging this gap are often discussed in the literature. First, at the firm level, firms can engage in cooperative $R \& D$ programs with research institutes creating an institutional link between these organizations and covering a variety of joint activities and programs (e.g. Brandstetter and Sakakibara 1998, Veugelers and Cassiman 2005). Except for finding a positive effect on overall innovation output (Belderbos et al. 2004), there is no clear evidence on the processes used to access basic research or on how it impacts innovation performance.

Second, at the inventor level, company inventors can interact with the scientific community directly to access basic research knowledge and translate it into more valuable commercial technologies. In biotechnology, for example, company inventors that publish scientific research are found to generate more valuable patents (Gittelman and Kogut 2003) and star scientists travel with their knowledge between academic and technology communities to assure the correct translation of this basic knowledge into new products and processes (Zucker and Darby 2001). Besides a few notable exceptions, little empirical work has explicitly examined who these boundary crossing inventors are and how and to what extent they can effectively bridge scientific and technology 
communities for the benefit of industrial R\&D (Allen 1977, Tushman and Scanlon 1981, Breschi and Catalini 2010).

We contribute to this literature in two ways. First, we attempt to identify the effect of these two important mechanisms that companies and inventors use to access basic research. Next to joining a cooperative basic research program at the institutional level, we also look at the importance of boundary crossing inventors, i.e. inventors that move between basic and applied research organizations. We look at the use of both mechanisms either exclusively or in combination, to identify any possible complementarity from embedding a boundary crossing inventor into an institutional partnership. A second contribution we make is that we examine different elements of the process through which firms might capture returns from linking to basic research. We compare the quality of the applied technologies they develop based on different mechanisms to bridge the gap with basic research. But we also look at how successful firms are in building further on these early stage technologies resulting from these different mechanisms that link to basic research.

In our empirical setting we measure these mechanisms to access basic research as interactions with IMEC, a world class research organization performing basic research in nano-electronics. First, by financially contributing to IMEC, firms can become an IMEC partner, i.e. buy "a seat at the table". IMEC runs an industrial affiliates program where partner firms then can sign up to specific research programs in their area of interest. Second, researchers participating in these basic research programs at IMEC interact with researchers of IMEC and other partners involved in the program and acquire "a spot in the lab" by doing basic research. ${ }^{1}$ Firms, IMEC partners or not, employ these researchers that have spent time at IMEC, i.e. a boundary crossing inventor. The analysis involves analyzing characteristics of company-owned patents which feature different treatments of these mechanisms to access basic research at IMEC at the partner and/or inventor level.

We find that firms linked to basic research through an IMEC partnership and who use boundary crossing inventors are more likely to develop higher quality innovations. Partner firms continue to build internally on these early stage technologies, improving appropriation of returns from follow-up technologies. Interestingly, these boundary crossing inventors are an important mechanism for bridging the gap with basic research, but only when used in combination with a partnership affiliation to IMEC. Poaching of these "IMEC inventors" by firms without a partnership link to IMEC is a less successful strategy. This complementarity between using boundary crossing inventors and having an institutional partnership is particularly important for further developing applied technologies based on this basic knowledge.

While our findings are derived from the analysis of the interaction with a particular research organization in microelectronics and semiconductors, we believe that they have more general appeal. They suggest the need to look at a number of mechanisms and a selection of outcomes to pin-point

\footnotetext{
${ }^{1}$ We thank Rosemary Ziedonis for suggesting this use of language.
} 
tangible effects for firms when drawing on basic research. Our paper most closely relates to the study of Ziedonis and Ziedonis (2005) on Sematech, a research consortium specialized in semiconductor manufacturing. While they also find positive effects from membership to Sematech, our IMEC research setting allows delving deeper into the type of mechanisms and the nature of effects of tying into basic research.

In the following section we discuss the gaps in the literature and develop some empirical predictions related to the process of how firms effectively appropriate returns for their innovation process through accessing basic research. Section 3 discusses the empirical setting of IMEC. Section 4 elaborates on our data development and methods while Section 5 presents our results. Section 6 concludes with some caveats and directions for further research.

\section{Bridging the Gap}

Because basic research is experimental or theoretical work undertaken primarily to acquire new knowledge without any particular application or use in view (OECD 2002), ${ }^{2}$ it is typically developed in institutional settings by organizations with broad objectives like universities and basic research organizations. This complicates the further development of basic research inside firms (Gittelman and Kogut 2003). Aghion et al. (2009) show that universities have more incentives to engage in early stage (basic) research as researchers value their autonomy in deciding the direction of the research projects and because the probability of successfully completing a commercial project is still low. Closer to commercialization firms are willing to step in and take over the projects as they have an incentive to direct this research towards completion. In addition, Lacetera (2009) argues that by outsourcing R\&D projects to universities, firms provide a credible commitment not to abort or alter projects with a more basic character and less certain commercial outcomes. University researchers working on these projects are responsive to the incentives defined by their community of peers. As a result, a gap between applied technology development at firms and more basic research in the public research environment needs to be bridged when basic research projects are handed off from one institutional setting to another and before basic research insights can be translated and developed into new applied technologies.

The tacitness of basic knowledge further complicates bridging this gap because tacit knowledge impedes the use of contracts as a mechanism to transfer this knowledge between

\footnotetext{
${ }^{2}$ The OECD Frascati manual (2002) provides the following definitions: Basic research is experimental or theoretical work undertaken primarily to acquire new knowledge of the underlying foundations of phenomena and observable facts, without any particular application or use in view. Pure basic research is research carried out for the advancement of knowledge, without working for long-term economic or social benefits and with no positive efforts being made to apply the results to practical problems or to transfer the results to sectors responsible for its application. Oriented basic research is research carried out with the expectation that it will produce a broad base of knowledge likely to form the background to the solution of recognized or expected current or future problems or possibilities. Applied research is original investigation undertaken in order to acquire new knowledge. It is, however, directed primarily towards a specific practical aim or objective.
} 
organizations. As Bessen (2011) argues, the tacitness of knowledge is endogenous. Organizations will only cover the cost of codifying knowledge whenever the benefit is sufficiently high. Hence, we should expect basic research knowledge to be less codified as it is harder to appropriate returns to this knowledge. For basic research, alternative transfer mechanisms, notably those involving transfer of people embodying the know-how, seem more appropriate to bridge between these two environments (Zucker and Darby 2001, Gittelman and Kogut 2003).

As a result, public policies around the globe attempt to promote active collaboration and personnel exchange between universities and industry, such as the NSF Grant Opportunities for Academic Liaison with Industry program or the Industry-Academia Partnerships \& Pathways of the Marie-Curie Program of the European Commission. In some occasions, new institutes are set up to stimulate this interaction, facilitating technology access and knowledge transfer while providing a repository for knowledge about the phenomena (Mokyr 2002).

\subsection{How to bridge the Gap?}

The literature has highlighted two mechanisms to transfer knowledge across organizational boundaries: firm level connections and "mobility" of individual researchers.

At the firm-level, the most widely studied mechanism is partnerships between firms and universities or other research organizations. The pre-eminence of cooperative agreements as a mechanism to access basic research is reminiscent of the importance of crossing institutional boundaries for effective knowledge transfers (Kogut and Zander 1992, Rosenkopf and Nerkar 2001). To study the effect of such cooperative agreements on firm performance, the largest set of empirical papers uses a knowledge production function approach (e.g. Audretsch and Stephan 1996, Zucker et al. 1998, Cockburn and Henderson 1998, Brandstetter and Sakakibara 1998). The empirical evidence from these studies confirm a positive effect from cooperation with universities and public research organizations on innovation productivity and innovative sales, at least for firms with own R\&D capacity (Belderbos et al. 2004, Belderbos et al 2006). This latter result supports the complementarity between cooperation with these research organizations and internal $R \& D$.

Beyond partnerships with research institutes, corporate ties with academic star scientists, such as through board positions, are found to lead to more patenting (Henderson and Cockburn 1996, Zucker et al 2002, Cockburn and Henderson 1998), more “important” patents: i.e. international patents (Cockburn and Henderson 1998), and a higher average of quality adjusted patenting at the firm level (Zucker and Darby 2001, Zucker et al 2002).

At the inventor level, those inventors co-publishing with universities or research organizations are found to generate patents that exploit more prominently (citations to) science, confirming their boundary spanning role. These inventors also produce patents with shorter lags between existing inventions and new firm inventions in the pharmaceutical industry (Fabrizio 2009). 
Moreover, the involvement of an academic inventor in the invention team tends to lead to more valuable patents (Czarnitzki et al. 2011).

Mobility of inventors or spanning organizational boundaries is related to better innovative performance of these inventors. More mobile researchers have better access to resources and networks (Cañibano, Otamendi and Andujar 2008) and consequently have a higher innovative performance (Hoisl 2007, Palomeras 2010). Firms hosting mobile researchers enjoy improved innovation performance (Song, Almeida and Wu 2003, Rosenkopf and Almeida 2003, Singh 2008), and even firms losing their inventors generate benefits from monitoring this tie to a new organization (Corredoira and Rosenkopf 2010, Oettl and Agrawal 2008). As a result, mobility across firm boundaries relates to more effective transfer of knowledge and higher innovative performance (Singh and Agrawal 2011).

While the existing firm level empirical analyses typically find a positive relation between basic research activities of the firm and innovation outcomes, these analyses pay little attention to the actual micro-level mechanisms that link basic research activity to innovation performance by leaving out the role of the inventor. At the same time the invention and inventor level analyses typically do not control for organization level connections of the firms such as partnership agreements the firm is engaged in. They limit themselves to an analysis of inventor networks without superimposing the different organizational structures in which these inventions and inventors are embedded, which will affect the incentives of these inventors to develop, communicate and appropriate returns to these basic research activities (Breschi and Catalini 2010). ${ }^{3}$

Based on the literature, we argue that spanning of organizational boundaries is needed to effectively access basic research and translate this into technological advances. Through inventors crossing organizational boundaries and, hence, bridging an institutional gap, frictions in this knowledge transfer process can be reduced.

In what follows, we will distinguish between two mechanisms of knowledge transfer: the boundary crossing inventor links and the more structured organization level partner links. More importantly, we will examine the interaction between firm and inventor level boundary spanning mechanisms, looking for a possible complementarity between both types of links at the invention level. While both partner and inventor links might be considered important to access basic research, the complementarity between them might be important for capturing the returns from tapping into basic research. Organizational level commitments provide the right incentives for researchers actively moving in and out of basic research to transfer their knowledge back to the organization and develop it into applied technologies.

\footnotetext{
${ }^{3}$ Rysman and Simcoe (2008) and Furman and Stern (2011) find interesting evidence of the effect of a particular institution (a standard setting organization or a biological resource center) on the quality of inventions or publications respectively. In our setting we add the complication that organizations play at the intersection of basic and applied research.
} 


\subsection{How to benefit from bridging the Gap?}

Any explanation for why firms want to tap into basic research knowledge needs to argue that ultimately basic research enhances firms' performance (Nelson 1959; Evenson and Kislev 1976, Cassiman, Perez-Castrillo and Veugelers 2002). Unfortunately, we still understand little about the actual processes of how firms incorporate and benefit from basic research knowledge. We propose two key steps in this process.

First, basic research enhances innovative performance by increasing the average quality of the technologies produced by the firm. Basic research serves as a map for technological landscapes guiding applied research towards the most promising technological directions avoiding thereby wasteful experimentation (Fleming and Sorenson 2004). A better and more fundamental understanding of the technology landscape encourages non-local search for improving technologies as opposed to local search, leading to more diverse research projects being explored with higher potential pay-offs. As discussed before, both firm level and inventor level links to basic research have been found to improve technological performance of the firm.

Second, firms will need to develop their basic research knowledge into more applied technologies closer to commercialization. Probably the most discussed argument of how actively engaging in basic research might increase applied research productivity is the fact that basic knowledge leads to a better identification, absorption and integration of external (public) knowledge (Cohen and Levinthal 1989, Gambardella 1995, Cassiman and Veugelers 2006). Faster identification, absorption and integration of external knowledge in turn leads to increased productivity of the applied research process, resulting into new technologies (Fabrizio 2009, Cassiman et al. 2008). This process of integration requires firms to develop the initially acquired technologies even further into applied technologies and eventually into products and processes leaving a trace of technologies linking the basic research knowledge to actual applied technologies of the firms. In addition, more basic knowledge can simultaneously fertilize different research projects (Henderson and Cockburn 1996), again requiring the firm to develop generic insights gleaned from basic research into more applied technologies and spurring additional technology development within the firm.

In summary, basic research should improve the quality of the applied technologies developed by firms. In addition, we would expect firms to take advantage of basic research by building on these knowledge flows through the internal development of commercially viable technologies and products. The process through which firms benefit from basic research, therefore, requires firms to set up mechanisms to bridge academic and technology communities and the institutional gap discussed before in order to access and develop higher quality technologies. In a next step these initial - more basic - technologies are further developed internally into more applied, but related technologies allowing firms to appropriate the actual returns from linking to basic research. 
In this paper, we will attempt to lay bare this process of how firms can capture value from linking to basic research and translating this basic research into applied technology development. By considering simultaneously the combination of different mechanisms - firm level and boundary crossing inventors - and different measures of capturing value from basic research - quality of initial technology and subsequent development of these technologies internally, we provide a first glimpse into this process. We do this for the case of a particular research organization in the nano-electronics field.

\section{Research Setting: microelectronics and IMEC}

In our analysis we focus on the micro-electronics industry and analyze the effect of links with IMEC the Interuniversity Microelectronics Center - a world class research institute with an explicit mission to bridge between basic research at universities and applied research in industry. IMEC performs oriented basic research that is likely to form the background knowledge to expected current or future technological applications 3 to 10 years ahead of industrial needs.

\subsection{Links to basic research in the micro-electronics industry}

The micro-electronics industry is an interesting environment for testing the effects of links of companies with basic research. First, academic research is often at the forefront of breakthroughs in nano-electronics, and for this reason companies are seeking to cooperate with universities and research institutes to tap into emerging research opportunities as early as possible. While academics are at the forefront of discoveries within their field, the challenge remains to bridge the large gap between the results from scientific research performed at universities and basic research institutes and the application-oriented needs of the industry .

Second, in the semiconductor business technological knowledge is mostly tacit in nature. Knowledge sharing via researcher interaction and mobility between firms and research organizations is shown to be the crucial mechanism to bridge this gap (Meyer-Krahmer and Schmoch 1998). In addition, patenting is a standard practice in this industry (Hall and Ziedonis 2001) and as a result, patents provide a clear window on the technology and innovation activity in the industry.

\subsection{IMEC as link to oriented basic research}

IMEC was founded in 1982 by the regional Flemish government in Belgium as a non-profit organization with a mission to be a world leader in oriented basic research in micro-electronics, bridging the gap between pure basis research at universities and R\&D in the industry.

The center was built on the academic reputation and prominence of the electrical engineering department of the University of Leuven. The center's involvement in the scientific community is illustrated by its close collaboration with world-class universities, by the numerous conference 
participations and publications from its researchers and by the presence of pre-doctoral researchers at its laboratories. ${ }^{4}$

At the same time, IMEC is closely connected to industry. The board of directors includes delegates from industry who stipulate the center's strategic roadmap focused on pre-competitive application-oriented technologies three to ten years ahead of industrial needs. IMEC was able to attract top industry leaders such as Intel, Samsung, Texas Instruments, Micron, NXP, Hynix, Elpida, Infineon, Panasonic, TSMC, Sony, Qualcomm and ST Microelectronics willing to pay the hefty fees to become a partner. Together with IBM in Albany, IMEC in Leuven has become one of the two most important centers for nano-electronic research with an important focus on process technologies. ${ }^{5}$

\subsection{IMEC's Industrial Affiliation Program}

IMEC has developed a unique business model which stimulates the interactions of scientific and industrial researchers in order to facilitate the cross-fertilization of knowledge and ideas. In IMEC's Industrial Affiliation Program participating companies engage in collaborative R\&D on more generic pre-competitive technologies, sharing costs, risks, human resources and intellectual property . Each partner firm can send researchers to collaborate in the programs in which the firm participates. Guest researchers, including academic and industrial researchers affiliated to one of its partners, conduct research at the IMEC laboratories in close collaboration with other researchers. Around 15 different industrial affiliation programs were running in 2010, of which a large majority in the Process Technology Unit, focused on the next generation of semiconductors. Besides IMEC's own research personnel (about 1,000), more than 520 guest researchers with 60 different nationalities were conducting research at IMEC’s laboratories in 2010, including 344 industrial researchers.

\subsection{IMEC's IPR-model}

Crucial for its Industrial Affiliation Program business model is an aligned Intellectual Property (IP)strategy so that all collaborating partners are able to build their own and unique IP-portfolio on top of shared IP. IMEC has elaborated an IP-strategy to stimulate this technology development and to limit blocking amongst its corporate partners (Van Helleputte and Reid 2004). ${ }^{6}$ The basic platform technologies are accessible to all its partners. These technologies, developed by IMEC or by IMEC in collaboration with partners, are still in a pre-competitive phase and require additional $R \& D$ to turn them into commercial technologies. Corporate partners can build on these technologies to develop proprietary IP in line with their own commercial needs. All technology developed at the IMEC

\footnotetext{
${ }^{4}$ In 2010, IMEC was collaborating with approximately 200 universities worldwide in its core CMOS (Complementary Metal Oxide Semiconductor) division only and hosted 194 visiting PhD students at its research facilities. IMEC's own researchers, around 1000, published more than 1,750 scientific articles in 2009.

${ }^{5}$ Unfortunately, the IBM partnership has no formally distinguishable form as the case of IMEC. As a result the data cannot be generated in a similar way to provide a nice empirical comparison of both institutions.

${ }^{6}$ Johan Van Helleputte is the director for strategic development at IMEC.
} 
laboratories, in execution of dedicated programs by academic or industrial researchers, is contractually co-owned by IMEC unless otherwise contractually stated. Partners gain access to these technologies, as far as needed for the exploitation of the program, via a non-exclusive and nontransferable license. Technologies which result from proprietary research activities within IMEC or at the company premises are assigned exclusively to the partner. These technologies should represent an important part of the return on the firm's investment in IMEC.

IMEC's business model and the corresponding IP-model are recognized worldwide as a successful medium to stimulate interaction between oriented basic research at a research organization and applied research efforts by the company. For our analysis, it allows to track the mobility of people and ideas around IMEC and its partners, as will be detailed in the next section.

\section{Data and Methodology}

\subsection{Data and Sample}

Our dataset is constructed by exploiting IMEC's basic IP-model. First, we collected all patent applications filed by IMEC between 1990 and 2005 which we retrieved from the Worldwide Patent Statistical Database (PatStat edition April 2008). This set of patents was validated by IMEC. ${ }^{7}$ From this sample of 578 IMEC patents, we identified 531 unique inventors - IMEC inventors ${ }^{8}$ - and we retrieved all subsequent patents in the complete patent database where these IMEC inventors are listed as an inventor. ${ }^{9}$ From this sample of subsequent patents we then identified all patents from IMEC inventors where the inventor was not on the IMEC payroll at the time of application for this subsequent patent and where a private company is the assignee of the patent. We name the IMEC inventors listed on these patents boundary crossing inventors as they have been active as an IMEC inventor in the generation of IP at IMEC at some point in their career and are not an IMEC employee at the time of patenting this subsequent company patent which implies some mobility event crossing organizational boundaries during the IMEC inventor's career. ${ }^{10}$ Finally, we also collected all

\footnotetext{
${ }^{7}$ These patents include 281 EPO, 255 USPTO and 42 PCT patent applications

${ }^{8}$ Note that given the structure of the IMEC programs these IMEC inventors are not necessarily formal IMEC employees as IMEC hosts many different types of researchers, including IMEC employees, affiliate partner employees, post-docs, doctoral students and master students, academic faculty. Inventors listed on patents have contributed to the invention, but do not necessarily have any legal right to the invention.

${ }^{9}$ All different name variants and corresponding person identification numbers of this set of inventors were retrieved using search keys to take into account different spellings. The match of inventor names was made based on matches of name, first name, initial and address. In the case of differences in addresses or names, we checked the technology field of the patent and the applicant name to determine a match. While this rigorous approach might lead to false negative matches (type I error), it minimizes/eliminates false positive matches (type II error). Given our objective to trace inventor interaction and mobility, this conservative approach seems more appropriate.

${ }^{10}$ IMEC has a database with all researchers which have been working at IMEC for at least one month (own personnel as well as visitors) and their status. The use of detailed personnel data obtained from IMEC for all IMEC inventors in our sample allows us to identify the affiliation of an inventor at a particular moment in time. Not all inventors in our sample were found in the database. For those which were potential boundary crossing inventors, we conducted a web search to find additional information on their employment. Inventors which were working for the assignee company at the time of patenting are treated as boundary crossing inventors while
} 
subsequent patents citing the set of 578 original patents owned by IMEC. These citing patents are posterior to the development of this IMEC technology but share the same technological space as the IMEC patents and, therefore, provide a reasonable comparison group for our selection of companyowned patents with a boundary crossing inventor from IMEC. ${ }^{11}$

Our final sample of company-owned patents consists of 1,089 USPTO patents - 221 patents with a boundary crossing inventor and 868 patents citing the original set of patents owned by IMEC. These patents are from 87 companies, of which 33 are IMEC partners and have 1,835 unique inventors of which 62 are boundary crossing inventors. ${ }^{12}$

Based on our sample construction we define four types of patents along two key dimensions:

Imec Inventor ${ }_{i f}(\in\{0,1\})$ indicates that patent $i$ of firm $f$ has a boundary crossing inventor and Imec Partner $_{\text {if }}(\in\{0,1\})$ indicates that patent $i$ is assigned to an IMEC partner firm, i.e. firm $f$ is an IMEC partner. ${ }^{13}$

The four patent types are:

- Boundary-Crossing-Partner patents are patents assigned to an IMEC partner company (i.e. a member of its Industrial Affiliation Program) and developed by a boundary crossing inventor, i.e. an inventor that has been active in the generation of IP at IMEC at some point earlier in his career but currently not an IMEC employee: ${ }^{14}$

$$
R_{i f}^{B C P}=\text { Imec Inventor }_{i f} \times{\text { Imec } \text { Partner }_{i f}}
$$

- Citing-Partner patents are patents assigned to IMEC partners citing at least one of the 578 IMEC-owned patents, but without being developed by a boundary crossing inventor:

$$
R_{i f}^{C P}=\left(1-\text { Imec Inventor }_{i f}\right) \times \text { Imec }_{\text {Partner }} \text { if }
$$

those for which we don't find information on their affiliation or who weren't working for the assignee company were excluded from further analysis.

${ }^{11}$ Note that the patents with a boundary crossing inventor do not necessarily cite any of the IMEC patents. But they have an inventor in common with at least one of these patents. In the robustness checks we will look at alternative comparison samples.

12 The initial sample consists of 5,802 patents (825 IMEC patents, 1,038 patents from IMEC inventors and 3,939 other patents citing IMEC patents), 7,566 unique inventors and 1,348 unique applicants, including around 1,200 companies, 82 universities and 66 research centers. For the remainder of the analysis, we restrict attention to USPTO patents only $(3,606)$ and subsequently eliminate patents (co)assigned to IMEC (302), patents not assigned to companies (488), patents from companies with less than 4 patents in our sample (502), patents which do not share the same technological space as the IMEC patents (65), patents assigned to boundary crossing inventors before they were at IMEC (288), for which we don't have all relevant characteristics (e.g. assignee information (546) or on the affiliation of the IMEC visiting researcher (326)). Note also that the set of 578 original patents owned by IMEC are only used to generate this sample of company-owned patents.

${ }^{13}$ In the robustness section we will deal with some obvious selection issues related to both partners and inventors.

${ }^{14}$ This inventor is listed as inventor on at least one of the 578 patents of the original set of patents owned by IMEC. 
- Boundary-Crossing-NonPartner patents are patents assigned to non-partner companies, but that have a boundary crossing inventor as an inventor on the patent:

$$
R_{i f}^{B C N P}=\text { Imec Inventor }_{i f} \times\left(1-{\text { Imec } \left.\text { Partner }_{i f}\right)}^{\text {In }}\right.
$$

- Citing-NonPartner patents are patents assigned to non-partner companies, citing IMEC patents but without being developed by a boundary crossing inventor.

$$
R_{i f}^{C N P}=\left(1-\text { Imec Inventor }_{i f}\right) \times\left(1-\text { Imec }_{\text {Partner }} \text { if }\right)
$$

The classification of the patents according to this methodology allows us to estimate the impact of boundary crossing inventors - a spot in the lab - and/or firm partnerships - a seat at the table - at the invention (patent) level. ${ }^{15}$ The strongest link is a combination of boundary crossing inventors and a partner link, as is the case for Boundary-Crossing-Partner patents. Patents that only have an institutional partner link with the research center are Citing-Partner patents, while BoundaryCrossing-NonPartner patents are patents with only an inventor link to IMEC. These are most likely poaching cases whereby a non-partner company hires away an IMEC inventor. Finally, CitingNonPartner patents don't have a partner nor inventor link except for the fact that these patents cite IMEC patents and, hence, were developed in the same technology space. These Citing-NonPartner patents are the ultimate control group for comparison with our various patent types. Note that in contrast to some of the literature, we do not argue that a citation by a company-owned patent to IMEC technology constitutes an explicit knowledge flow. We use citations only for identifying patents that are related in technology space and, hence, provide an even tighter control on the type of technologies considered. In the robustness check we will also consider a more common control group of patents of the same application year and within the same technology class.

Table 1 below shows the classification of the types of patents according to the links with IMEC and the number of observations for each type.

Insert TABLE 1 here

\subsection{Empirical Model}

By classifying all patents according to boundary crossing inventor and/or partnership links with IMEC, using the Citing-NonPartner patents as the base case, we can estimate the impact of different mechanisms to bridge the gap with basic research at IMEC and their interactions. As the earlier discussion suggests, we consider different outcomes as measures of the effects of these inventor and/or partner links with IMEC. The basic empirical model and the hypotheses tests have a similar structure across the outcomes considered, as described below.

\footnotetext{
${ }^{15}$ Note that these Citing Patents necessarily are developed after the background technology of IMEC has been developed. Similarly, patents with boundary crossing inventors have been developed after the inventor passed through IMEC.
} 
Let $V_{i f}$ be our dependent variable which measures a key characteristic of patent $i$ of firm $f$. We estimate a regression of the following form:

$$
V_{i f}=\alpha+\beta_{p} P_{i f}+\gamma_{F} F_{f(t)}+\sum_{x \in\{B C P, B C N P, C P, C N P\}} \theta_{x} R_{i f}^{x}+\delta_{k}+\mu_{t}+\epsilon_{i f}
$$

Where

$$
\begin{aligned}
& P_{i f}=\text { Patent level variables, } \\
& F_{f(t)}=\text { Firm }- \text { Year variables } \\
& \delta_{k}=\text { Technology Class Fixed Effect } \\
& \mu_{t}=\text { Year Fixed Effect }
\end{aligned}
$$

The $\theta_{x}$ where $x \in\{B C P, B C N P, C P, C N P\}$, are our key parameters of interest in these regressions. Earlier work has found that either partner links or boundary crossing inventor links affect $V_{i f}$. Our more refined empirical predictions from Section 2 on the effects of mechanisms for bridging the gap between basic research and applied research discussed earlier can be translated in the following tests.

\section{Link Test:}

- A Boundary Crossing Inventor link matters; both for partner and non-partner firm patents:

$$
\theta_{B C P}>\theta_{C P}(L T 1.1) ; \theta_{B C N P}>\theta_{C N P}(L T 1.2)
$$

- A Partner link matters both for boundary crossing inventor patents and non-boundary crossing patents:

$$
\theta_{B C P}>\theta_{B C N P}(L T 2.1) ; \theta_{C P}>\theta_{C N P}(L T 2.2)
$$

Complementarity Test: Complementarity exists between Partner and Inventor Links when:

$$
\theta_{B C P}-\theta_{C P}>\theta_{B C N P}-\theta_{C N P}(\mathrm{CT})
$$

i.e. the effect of a boundary crossing inventor link will be stronger for a partner firm than for a nonpartner firm.

\subsection{Dependent Variables}

We consider two types of effects of these two mechanisms to bridge the gap with basic research on the innovation process of the firm: quality of inventions being developed subsequently to the linking activity and the internal translation and subsequent development effort by the firm. 


\subsubsection{Quality of Invention}

To evaluate the effect of linking to basic research through IMEC on the technological impact and the economic value of an organization's patents, we employ a commonly used indicator in past studies to measure patent quality. The most used indicator of patent value and quality is the number of forward citations received from subsequent inventions (Trajtenberg 1990; Harhoff et al. 1999; Gambardella et al., 2008). We calculate the total of all forward citations received by an individual patent since the year of application. We also use a fixed citation window of 3 years after application.

We expect a positive correlation between boundary spanning links and forward citations, i.e. Boundary-Crossing and/or Partner patents are expected to have a higher rate of forward citations as compared to the base case of Citing-NonPartner patents. Comparing Boundary-Crossing-Partner patents with Citing-Partner patents would test for the additional effect of a boundary crossing inventor link for partner firms (LT1.1) while comparing Boundary-Crossing-NonPartner patents with Citing-NonPartner patents would test for this effect for non-partners (LT1.2). Comparing BoundaryCrossing-Partner with Boundary-Crossing-NonPartner patents would test for the additional effect of an institutional partner link for firms using a boundary crossing inventor link (LT2.1) while comparing Citing-Partner patents with Citing-NonPartner patents would test for this link for firms not using a boundary crossing inventor link (LT2.2).

If inventor and partner links are fully complementary, i.e. boundary crossing inventor links are more effective for partners and/or partners get more value out of boundary crossing inventors, we have that the marginal effect of a crossing inventor on a partner patent is larger than the marginal effect of such an inventor for non-partners (CT).

To estimate the technological impact of the patents as measured by their number of forward citations, we use count models as the dependent variable is a non-negative integer. The specification of our baseline model as a Poisson or a Negative binomial model follows previous studies. We first estimate the Poisson quasi-maximum likelihood model (PQML) because this renders consistent estimates given that the mean is correctly specified (Gouriéroux et al. 1984). We also use a Negative Binomial model which allows for overdispersion and heterogeneity across observations. Moreover, our sample has a large number of observations with zero value (31\% of 1,089 patents). To deal with this issue, Zero-Inflated Poisson (ZIP) and Negative Binomial models (ZINB) are also estimated (Long 1997).

\subsubsection{Internal Development Effort}

Firms working in a particular technology area can build on their internal knowledge and technology. Self-citations - citations by an organization to their own prior art technologies - reflect this capacity of the firm to build further on its existing internal technologies (Hall, Jaffe, and Trajtenberg 2001, 2005, Jaffe and Trajtenberg 2002). We calculate the proportion of forward citations of our sample 
patents that are self-citations as an indicator for the extent to which both these mechanisms - inventor or partner links - encourage firms to build forward on these technologies. Hence, the proportion of self-citations reflects the extent to which the company is able to, or attempts to appropriate the returns of bridging the gap with basic research. ${ }^{16}$

We expect firms with links to IMEC to have a higher capacity and incentive to build further on IMEC related internal knowledge. In particular, comparing Boundary-Crossing-Partner patents with Boundary-Crossing-NonPartner patents (LT2.1) and Citing-Partner patents and CitingNonPartner patents (LT2.2) tests for the importance of a partner link with IMEC. Comparing Boundary Crossing-Partners with Citing-Partners (LT1.1), tests for the additional effect of an inventor link next to an institutional link. These inventor and organizational links are complementary when boundary crossing inventor links are more effective for partners and/or partners can appropriate better with boundary crossing inventor links (CT).

To estimate the importance of building further internally on IMEC related technology we regress the proportion of self-citations of the patent on our control variables and patent indicators for the type of link with IMEC, while controlling for the total number of forward citations received. We use OLS and heteroskedastic Tobit models.

\subsection{Control Variables}

To obtain consistent estimates, we include control variables at the patent level and firm level. At the patent level, we first control for 30 patent technology classes as defined by Fraunhofer (FhG-ISI, Germany) based on concordance with IPC codes (OECD 1994). Different technological classes are characterized by different citation patterns, both in the amount and the scope of citations to patents and scientific literature.

Second, we control for changes in citation patterns over time and for truncation by including application year dummies. In addition, we introduce patent scope as the number of International Patent Classification (IPC) codes listed on the patent. Patent scope could determine the extent of patent protection and monopoly power and thus the economic value of an invention (Scotchmer 1991). At the same time, more IPC classes covered by the patent could also affect the likelihood of being cited as the patent covers more technology space. The count of citations to scientific work (NPRS) is included as an additional control as more references to scientific work are associated with a higher number of received citations merely because the act of publication allows the ideas underlying the patent to diffuse more broadly and rapidly (Fleming and Sorenson 2004) or because of possible higher economic value of these patents (Harhoff et al. 2003). Similarly, we control for the number of

\footnotetext{
${ }^{16}$ See also Alcacer and Zhao (2012) where they argue that the regional dispersion of inventors on self-citations allows firms to appropriate returns from inventions in different regions depending on the competitive environment of the region of the focal invention.
} 
backward patent references to control for unobserved factors affecting citation behavior (Reitzig 2004).

We include the number of inventors as an additional control because more inventors might lead to a faster and greater diffusion of the tacit and complex knowledge underlying the patent, resulting in different forward citation patterns. This measure is also used to control for the resources invested in developing the technology.

We include for each patent inventor his experience to control for a potential inventor selection issue. Particular types of technologies might be developed by more competent or experienced researchers. We calculate inventor experience as the number of patents filed at the USPTO by the inventors of the focal patent before the application year. We made use of "the careers and coauthorship networks of U.S. patent-holders” data (Lai, D’Amour and Fleming 2009) to identify inventor histories.

Next, we introduce for each patent additional measures on the organization of R\&D at the firm level to control for firm specific variation at the time of patent application. ${ }^{17}$ Several arguments have been advanced as to why organization size matters for research productivity. First, larger organizations wield more resources and are able to exploit economies of scale in research (Cassiman and Veugelers? 2005). Cassiman, Perez-Castrillo and Veugelers (2002) find that larger firms have an incentive to proportionally invest more in basic research as it increases the productivity of applied R\&D. Second, larger organizational size allows more specialization. In larger firms, researchers work on more projects but are more specialized in the type of projects they engage in (Kim and Marschke 2009). Third, larger companies are able to exploit economies of scope. As larger firms are active in different product markets and technology domains, more opportunities for exploiting economies of scope within the firm arise (Henderson and Cockburn 1996). Scale is calculated as the number of US patents filed by the firm in the 5 years before the application year of the focal patent and Scope as the number of distinct IPC codes of a company's patents in the 5 years before the application year of the patent. Finally, Age Company is included as the number of years since the company's first patent at the moment of the filing of the focal patent. Sørenson and Stuart (2000) find that on the one hand older firms produce more patents, but on the other hand these same firms produce less valuable patents. Moreover, older firms self-cite more and have older backward citations. ${ }^{18}$

\footnotetext{
${ }^{17}$ These firm-level variables vary across different patents of the same company applied for at different moments in time. They are calculated at the company application year level.

${ }^{18}$ Note that their interpretation of self-citations does not correspond to our notion of appropriation in science intensive businesses. See also Catani (2005) for a similar interpretation as ours of self citations in optical fiber technology.
} 


\section{Results}

\subsection{Descriptive analysis}

Table 2 presents some descriptive statistics for the total sample, while Table 3 gives an overview of descriptive statistics by patent type. The IMEC-owned patents from which we build our sample are more likely to cite the scientific literature (non-patent reference binary), confirming the more sciencedriven basic research nature of these patents. But at the same time our selection of company-owned patents from IMEC partners and non-partner firms are significantly more likely to cite scientific literature compared to an average US patent which is about $30 \%$.

Insert TABLE 2\&3 here

When we look at the partner and non-partner patents, we see that Boundary-Crossing-Partner patents, which have both a boundary crossing inventor and an institutional partner link to IMEC, receive the highest number of forward citations. This is particularly clear when we restrict the citation window to 3 years, controlling for the exposure time of patents. Citing-Partner patents with only an institutional partner link to IMEC, but without the boundary crossing inventor link, are as likely as Boundary-Crossing-Partner patents to receive forward citations, but the count of these citations is lower. $^{19}$

Both Boundary-Crossing-Partner and Citing-Partner patents are more likely to be built upon internally compared to non-Partner patents, suggesting that partners are more likely to continue developing technology in the IMEC related areas. Self-citations to these patents are much higher. ${ }^{20}$

In summary, these first descriptive results already indicate that the tighter the link with IMEC, the more able a company seems to assimilate the knowledge captured by the invention and to use this knowledge to develop subsequent inventions. We argued that because of the tacitness and complexity of know how underlying leading edge research, researcher interaction and mobility does play an essential role. We indeed observe that individual inventors having been at the research center collaborating with other industrial and scientific researchers in joint R\&D projects - i.e. boundary crossing inventors - seem to play a significant role as link between industry and IMEC, but most importantly when they are associated with firms that have an institutional partnership link with IMEC. These descriptive statistics, although not controlling for other factors, are already supportive for the positive impact of IMEC links for firms' technology development, particularly the combined inventor and partner link. Maybe more surprising given all the literature on inventor networks and mobility is the finding that a boundary crossing inventor does not seem to result in higher quality technologies being captured and developed when he is operating outside an institutional partner link.

\footnotetext{
${ }^{19}$ Ttest on difference of means Boundary-Crossing-Partner vs Citing-Partner: count forward citations within 3 year: $\mathrm{t}=3.83^{* * *}$;

${ }^{20}$ Ttest on difference of means Boundary-Crossing-Partner vs Boundary Crossing-NonPartners:t=2.98***; Citing-Partner vs Citing-NonPartners:t=3.23***
} 


\subsection{Quality of Invention}

Table 4 shows the results of our count model estimations: Poisson (1 \& 2), Negative Binomial (3) and Zero-inflated Negative Binomial (4). Regressions (5) and (6) where we estimate a (Zero-inflated) Poisson Count model and use the forward citations received in a 3-year window as the dependent variable are probably the most stringent specifications. Boundary-Crossing-Partner patents receive between $46 \%$ and $94 \%$ more citations compared to the control group of Citing-NonPartner patents depending on the model selected. For firms that are not IMEC partners, patents developed with the assistance of boundary crossing inventors, are not more valuable compared to patents developed without the assistance from boundary crossing inventors. Our expectation that boundary crossing inventors are a pivotal mechanism for linking therefore only seems to hold for firms that also have an institutional link. This is confirmed by the significance of the LT2.1 test in regressions (5) and (6), which states that a boundary crossing inventor will have a higher effect for partnering than for nonpartnering firms. These results are supportive for complementarity between partner and boundary crossing inventor links. The formal test for complementarity is however only significant at $7 \%$ for the fixed citation window results (regression (5)).

\section{Insert TABLE 4 here}

As expected, the scope of the patent (Count IPCs) and the number of scientific publications cited by the patent (NPRS) are positively related with the number of forward citations received, while the age of the company is negatively related. Scale of the firm is positive and Scope of the firm is negative, but these coefficients are not estimated precisely across all regressions.

\subsection{Internal Development Effort}

Building further on technology linked to IMEC technologies is an important way to capitalize and appropriate returns from linking to basic research. As expected, IMEC partners are more likely to build further on these technologies, as indicated by the higher proportion of self-citations received by both Boundary-Crossing-Partner and Citing-Partner patents (See Table 5). This result is in line with Ziedonis and Ziedonis (2005), which find that member firms of the SEMATECH consortium are building upon the results of their collective research to a greater degree than are non-member firms. These patents are estimated to have on average a $6 \%$ to $12 \%$ larger proportion of self-citations relative to comparable patents by non-partners. Although we find that partner patents with a boundary crossing inventor link have a larger proportion of self-citations compared to patents of partners without a boundary crossing inventor link, this difference is not statistically significant (LT1.1). There is, hence, no evidence of significantly higher effects from the inventor link for partnering firms with respect to the proportions of self-citations. A patent from a non-partnering firm but with a boundary spanning inventor link actually has a significantly smaller proportion of self-citations compared to patents from boundary spanning inventors at partner firms (LT2.1) or from citing non-partner patents 
(LT1.2). This result seems to suggest that if there is no institutional link with IMEC the hiring company is not able to fully appropriate the return to its investments relative to others by building forward on the technologies developed by this researcher. Being able to fully exploit the researcher mobility link seems to require a complementary institutional link.

All these findings are supportive of the complementary role of boundary spanning inventors and institutional partnerships in order to better absorb the complex and tacit technological knowledge underlying micro-electronics research through the internal development of the next generation of technologies. The test for complementarity is indeed statistically significant at the $1 \%$ and $1.1 \%$ level for the Tobit regressions that control for censoring of our dependent variable.

\section{Insert TABLE 5 here}

The count for forward citations is highly significant and positive as a control. Scope of the firms is negatively related to the proportion of self-citations. Together with the negative effect of scope on the number of forward citations received this might indicate a loss of focus for the firms with broader scope. The number of backward patent citations (PRS) is positively related to the proportion of selfcitations. Our results are consistent across the different specifications.

\subsection{Robustness \& Selection}

\subsubsection{Robustness}

Our measure for the quality of patents is the number of forward citations while our measure of internal development effort is the proportion of these forward citations that are self-citations. One potential concern is that our quality measure is actually driven by the number of self-citations rather than by the total citations received by the patent. In Table 4, in regressions (7) and (8) we re-estimate our specification for forward citations without self-citations in a 3-year window and for self-citations in a 3-year window as a Zero-Inflated Poisson estimation (ZIP). We do find some interesting differences comparing regressions (7) and (8). Consistent with our findings on the proportion of selfcitations in total forward citations, both Boundary-Crossing-Partner patents and Citing-Partner patents have a significantly higher number of self-citations compared to Citing-NonPartner patents and Boundary-Crossing-NonPartner patents. When only taking into account citations coming from other firms (regression (7)), we find that Boundary-Crossing-Partner patents have a significantly higher number of forward citations in this specification but not Citing-Partner patents. These results allow us to better interpret the results on the proportion of self-cites. For Boundary-Crossing Partner

patents, the strong positive effect on the number of citations results from a combination of positive effects on self-citations and external citations. For Citing-Partner patents the positive effect on the number of citations is due a positive effect on number of self-citations only, while external citations are not significantly affected. For Boundary-Crossing-Non-Partner patents, the negative effect on self-citation rates is from a negative effect on the number of self-citations, while the coefficient on 
external citations is positive but not significant. These findings are consistent with our interpretation of the results that a combination of boundary crossing inventors and an institutional partnership link is important to develop high quality inventions based on their IMEC relation while firms with an institutional partnership link invest more effort in internally developing IMEC related technologies.

\subsubsection{Sample Selection}

Our results on the positive effect of boundary crossing inventor links and partner links on the quality of inventions and the self-citations might be sensitive to the control sample of patents selected. As mentioned, we construct our control sample for the sample of boundary crossing patents based on a set of patents that cite IMEC-owned patents. We argued that this helped to construct a sample of patents in the relevant technology field for IMEC related technologies. However, one might worry that this selection procedure excludes parallel but independent technology trajectories or might introduce a particular bias related to citing behavior of firms. We check the robustness of our findings by constructing a more standard control sample of patents sharing the same technology class (IPC4) as the focal patents. Among the group of matching patents based on technology class, we select for a Boundary-Crossing-Partner patent in our sample a control patent with the closest application date and belonging to an IMEC partner, effectively matching the patent on technology class, application year and the fact that it belongs to an IMEC partner. The only difference is the fact that the technology is not developed by an IMEC inventor. For Boundary-Crossing-NonPartner patents we follow the same procedure with the only difference that the control patent is assigned to a non-partner company.

We also perform a second check by restricting our actual sample to patents that only cite IMEC-owned patents, i.e. we also restrict the patents with a boundary crossing inventor to patents that also cite IMEC-owned technology. Table 6 presents the descriptive statistics for these two samples together with our original descriptive results. Our results remain valid, but the small sample size precludes us from obtaining significant results for all samples.

Insert TABLE 6 here

Interestingly, comparing the columns "Citing” and "Control IPC-Year" in Table 6, the control groups based on IPC and year have an average 3-year citation count and self-citation proportion for partner patents that is comparable to or lower than our control group of citing patents. This reassures us that our control group based on citing patents is probably more conservative. When restricting the sample to all patents that cite IMEC-owned technology, comparing "Boundary Crossing Inventor" and "Boundary Crossing Inventor Citing” for IMEC partners and non-partners, the samples show nonsignificant differences in the average 3-year forward citation counts of 4.25 compared to 4.42 in the case of a partner patent and 1.44 compared to 1.69 for a non-partner patent. But one should note the low number of observations for the boundary crossing inventor patents that also cite the original 
IMEC technologies which is somewhat surprising. This precludes us from running the full regression on this second sample.

Table 4 (regression 9) and Table 5 (regressions 5) show the results for the same regressions using the matched IPC- application year patents as a control for boundary-crossing partner patent and boundary-crossing non-partner patents. As expected from the descriptives, our results hold up with this alternative control group and are even stronger. Boundary-Crossing-Partner patents are predicted to receive $127 \%$ more citations compared to comparable patents of non-partner companies while Boundary-Crossing-NonPartner is not significant (see Table 4 where regression 9 replicates regression 5). For the proportion of self citations, we find Boundary-Crossing-Partner patents on average have a proportion which is 0.12 higher while the "control" Partner patents on average have a proportion which is 0.16 higher compared to the matched control group of non-partner patents. ${ }^{21}$

\subsubsection{Partner and Inventor Selection}

While the empirical results are supportive for the tangible effects of links with IMEC, particularly for the combination of inventor and organizational spanning mechanisms, we need to address potential selection issues at the level of the partner firm and the inventor.

A first important concern is that the positive effect of the partner link on patent quality and in particular on self-citations might be driven by elements that favor a company being a partner rather than the effect of the partner link per se. In an attempt to more formally control for this partner selection issue, we estimated the probability of a particular patent to be from an IMEC partner at a particular moment in time in function of patent characteristics, the company's core technological area, ${ }^{22}$ the location of its headquarters (USA/Europe/Japan), whether the firm is in the top 25 of largest semiconductor firms as well as its scale, scope and age as defined before. The selection model (see Appendix) results in a pseudo $\mathrm{R}^{2}$ of 0.45 and we make $82 \%$ correct predictions. ${ }^{23}$ Consequently, we calculate the propensity scores to be a partner patent and use kernel matching to compare different matches of patents to examine the robustness of our findings. Results are presented in Table 7.

\section{Insert TABLE 7 here}

The matched patents basically reveal a similar story as our regressions. Compared to the benchmark case of Citing-NonPartner patents, the superior performance of Boundary-Crossing-Partner patents is

\footnotetext{
${ }^{21}$ For ease of comparison we have shown the results of the regression with the alternative control group in our earlier tables. Note, however, that behind the label "Citing Partner" patents are actually matched patents of an IMEC partner firm in the same technology class and with the same application year as the Boundary-CrossingPartner patents. The omitted control group consists of matched non-partner patents from same technology class and application year as the Boundary-Crossing-NonPartner patents. For this check we also did not calculate all the firm level variables and inventor experience of these randomly selected patents.

${ }^{22}$ Electrical machinery and apparatus, electrical energy; audio-visual technology; telecommunications; information technology; Semiconductors; optics; analysis, measurement, control technology; chemical engineering

${ }^{23}$ The constant only model would correctly assign $56 \%$ of the patents.
} 
confirmed: boundary crossing inventors of partners matter for the quality of the technologies developed as shown for the forward citations. The effect of a partner link, i.e. comparing CitingPartner patents to Citing-NonPartner patents, shows a significant positive effects on self-cites only, effectively testing LT2.2 for this outcome measure. The results from comparing Boundary-CrossingPartners to Boundary-Crossing-NonPartners, i.e. the additional effect of partnership for inventor links, i.e. testing LT2.1, confirms a significantly higher effect from Boundary-Crossing-Partner patents on average quality as well as on self-citations. These results thus confirm the importance of an institutional link to exploit the advantages of an inventor link, even when more carefully controlling for partner selection through our matching procedure.

A second important concern beyond the partner selection issue is that there might also be an inventor selection issue in case firms would send their more competent researchers to IMEC resulting in the higher perceived quality of boundary crossing partner patents. From interviews with managers from IMEC we learned that this is not necessarily the case because companies do not want to share their most valuable human resources with other firms - including competitors - while at the same time making sure that the participating researchers are able of identifying, absorbing and integrating the relevant knowledge. IMEC does attempt to control selection behavior by providing partners with regular evaluations of the boundary crossing researchers in the IMEC teams. We attempt to check the inventor selection issue by matching the prior patents of IMEC-visiting researchers in our sample, i.e. prior to these visits, with a group of comparable patents applied for by the same firm within the same year. We only had a small sample of 19 inventors for which we could perform such analysis, but results obtained from T-tests indicate that the paired group of patents do not differ significantly, ${ }^{24}$ suggesting that there is no obvious inventor selection issue. ${ }^{25}$

\section{Discussion and Conclusion}

IMEC partners develop higher quality technologies in the technology domain where IMEC is active. Furthermore, these partner firms are more likely to build on these technologies internally. However, we have found that boundary crossing inventors, i.e. researchers of a partner actively engaged in joint research with IMEC are an important link in this chain as they allow the partner to develop higher quality technologies internally and allow partners to capitalize on the returns from bridging this gap with basic research through internal development of the next generation of commercial technologies. The technologies developed by the boundary crossing inventors are extensively used internally as a platform for further technology development by these IMEC partners.

\footnotetext{
${ }^{24}$ We found no statistically significant differences between the number of citations received within three years (3.69 for patents before visit inventor compared to 2.83 for control group, $\mathrm{T}=0.133$ ), the proportion of selfcitations ( 0.14 versus 0.13 for control, $T=0.7379$ ), the number of IPC codes ( 3.59 versus 3.49 , $T=7653$, the number of backward patent citations (10.66 versus 11.49 , $\mathrm{T}=0.559$ and the number of non-patent references (1.74 versus $1.76, \mathrm{~T}=0.962)$.

${ }^{25}$ In the case that partners are likely to send less competent researchers, this would actually bias the results against us.
} 
As these effects from boundary crossing inventor links are significantly stronger for firms that have a partnership link with IMEC, this suggests that companies should have a complementary institutional link to benefit from cross-institutional employee interaction and mobility, for establishing cumulative technology development. Hence, boundary crossing inventor links do not tell the whole story. Firms need to buy a seat at the table before acquiring a spot in the lab seems to have any effect. These results would suggest that some of the recently initiated programs by policy makers such as the NSF Grant Opportunities for Academic Liaison with Industry program or the Industry-Academia Partnerships \& Pathways of the Marie-Curie Program of the European Commission will only be successful if embedded within tighter institutional mechanisms linking university and firm.

Our paper confirms results found by Ziedonis and Ziedonis (2005) for the similar case of Sematech, namely that technologies developed by the consortium or one of its partners are more valuable, particularly for members who build on these patents more extensively and more rapidly compared to non-members. But being able to track the movement of inventors and identify effects separately, allows us to further refine these results by showing the importance of combining a boundary crossing inventor link with a link at the institutional level.

Our results are highly supportive of the paper's research strategy to differentiate among the bridging mechanisms - boundary crossing inventors and partnerships - as well as the impact measures - forward citations and proportion of self-citations. At the same time they also suggest important avenues for further research. First, the analysis should extend the set of mechanisms to bridge the gap with basic research (e.g. co-publications). Secondly, more information on how firms organize internally for effectively linking from case studies at partnering and non-partnering firms would be helpful to further fine tune the search for institutional controls on the effects and the partner selection analysis. Particularly, critical company characteristics beyond the scale and scope of R\&D and the age of a company need to be factored into explain actual appropriation success. Given our data we are unable to determine eventual commercial success of these technologies. Our interviews did indicate important lags in generating actual commercial results. Furthermore, many of the technologies developed relate to process technologies used by the companies internally and which are difficult to value commercially. Thirdly, in order to better understand what makes the IMEC model so successful, a more in-depth study of IMEC is in order. As IMEC is not characterized by major regime shifts over time which would allow pin-pointing critical characteristics for success, comparing with other research consortia formula is a more promising avenue to understand what makes IMEC special. Sematech and the Micro-electronics and Computer Technology Corporation for instance, are alternatively consortia models in semiconductors which differ sufficiently in terms of IP model, public and private funding, and, collaboration model as well as in their success to make for a fruitful comparison analysis (Cassiman 1996; Ziedonis and Ziedonis 2005). 


\section{References}

Aghion, P., M. Dewatripont, J. Kolev, F. Murray, S. Stern. 2009. Of Mice and Academics. Mimeo Harvard University, Cambridge, MA.

Alcácer, J., M. Zhao. 2012. Local R\&D Strategies and Multi-location Firms: The Role of Internal Linkages. Management Sci. 58(4) 734-753.

Allen, T. J. 1977. Managing the flow of technology. MIT Press, Boston, MA.

Audretsch, D.B., P.E Stephan. 1996. Company-Scientist Locational Links: The Case of Biotechnology. Amer. Econom. Rev. 86(3) 641-652.

Belderbos, R., M. Carree, B. Lokshin. 2004. Cooperative R\&D and Firm Performance. Res. Policy. 33(10) 1477-1492.

Belderbos, R., M. Carree, B. Lokshin. 2006. Complementarity in R\&D Cooperation Strategies. Review of Industrial Organization. 28(4) 401-426.

Bessen, J. 2011. From Knowledge to Ideas: The Two Faces of Innovation. Working paper No. 10-35, Boston University School of Law .

Brandstetter, L., M. Sakakibara. 1998. Japanese research consortia: a microeconometric analysis of industrial policy. J. Indust. Econom. 46: 207-233.

Breschi, S., C. Catalini. 2010. Tracing the links between science and technology: An exploratory analysis of scientists' and inventors' networks. Res. Policy. 39(1) 14-26.

Butler, D. 2008. Crossing the Valley of Death. Nature. 453 840-842.

Cañibano, C., J. Otamendi, I. Andujar. 2008. Measuring and Assessing Researcher Mobility From CV Analysis: the Case of the Ramon y Cajal Programme in Spain. Research Evaluation. 17(1) 17-31.

Cassiman, B. 1996. Cooperation in Research and Development. Ph.D. thesis, Northwestern University, Evanston, IL.

Cassiman, B., D. Perez-Castrillo, R. Veugelers. 2002. Endogenizing Know-how Knows through the Nature of R\&D Investments. International Journal of Industrial Organization. 20(6) 775-799.

Cassiman, B., R. Veugelers. 2006. In Search of Complementarity in the Innovation Strategy: Internal R\&D and External Knowledge Acquisition. Management Sci. 52(1) 68-82.

Cassiman, B., R. Veugelers, P. Zuniga. 2008. In search of Performance Effects of (in)direct Industry Science Links. Indust. Corporate Change. 17(4) 611-646.

Cattani, G. 2005. Preadaptation, Firm Heterogeneity, and Technological Performance: A Study on the Evolution of Fiber Optics, 1970-1995. Organ. Sci.. 16(6) 563-580.

Cockburn, I.M., R. Henderson. 1998. Absorptive Capacity, Coauthoring Behavior, and the Organization of Research in Drug Discovery. The J. Indust. Econom. 46(2) 157-182.

Cockburn, I., R. Henderson, S. Stern. 2000. Untangling the Origins of Competitive Advantage. Strategic Management J. 21 1123-1145.

Cohen, W.M., D.A. Levinthal. 1989. Innovation and learning: the two faces of R\&D. The Economic Journal. 99(397) 569-596.

Cohen, W.M., R. Nelson, J. Walsh. 2002. Links and impacts: The influence of public research on industrial R\&D. Management Sci. 28(1) 1-23.

Corredoira, R., L. Rosenkopf. 2010. Should Auld Acquaintance Be Forgot? The Reverse Transfer of Knowledge through Mobility Ties. Strategic Management J. 31(2) 159-181.

Czarnitzki, D., K. Hussinger, C. Schneider. 2011. Commercializing Academic research: The Quality of Faculty Patenting. Indust. Corporate Change. 20(5) 1403-1437.

Evenson, R.E., Y. Kislev. 1976. A Stochastic Model of Applied Research. J. Political Econom. 84(2) 265-282.

Fabrizio, K. 2009. Absorptive Capacity and the Search for Innovation. Res. Policy. 38(2) 255-267.

Fleming, L., O. Sorenson. 2004. Science as a map in technological search. Strategic Management J. 25 909-928.

Furman, J.L., S. Stern. 2011. Climbing atop the Shoulders of Giants: The Impact of Institutions on Cumulative Research. Amer. Econom. Rev. 101 1933-1963.

Gambardella, A. 1995. Science and innovation: the US pharmaceutical industry during the 1980s. Cambridge University Press, Cambridge, U.K.

Gambardella, A., D. Harhof, B. Verspagen. 2008. The value of European patents. European 
Management Review. 5 69-84.

Gittelman, M., B. Kogut. 2003. Does Good Science Lead to Valuable Knowledge? Biotechnology Firms and the Evolutionary Logic of Citation Patterns. Management Sci. (49)4 366-382.

Gourieroux, C., A. Monfort, A. Trognon. 1984. Pseudo Maximum Likelihood Methods: Applications to Poisson Models. Econometrica. 52(3) 701-720.

Hall, B.H., R.M. Ziedonis. 2001. The determinants of patenting in the US semiconductor industry, 1980-1994. RAND J. Econom. 32(1) 101-128.

Hall, B. H., A. B. Jaffe, M. Trajtenberg. 2001. The NBER Patent Citation Data File: Lessons, Insights and Methodological Tools. Working paper 8498, National Bureau of Economic Research, Cambridge, MA.

Hall, B.H., A. Jaffe, M. Trajtenberg. 2005. Market Value and Patent Citations. RAND J. Econom. 36(1) 16-38.

Harhoff, D., F. Narin, F. Scherer, K. Vopel. 1999. Citation Frequency and the Value of Patented Inventions. The Review of Economics and Statistics. 81(3) 511-515.

Harhoff, D., F. Scherer, K. Vopel. 2003. Citations, Family Size, Opposition and the Value of Patent Rights - Evidence from Germany. Res. Policy. 32(8) 1343-1363.

Henderson, R., I.M. Cockburn. 1996. Scale, Scope, and Spillovers: The Determinants of Research Productivity in Drug Discovery. RAND J. Econom. 27(1) 32-59.

Hoisl, K. 2007. Tracing Mobile Inventors- The Causality between Inventor Mobility and Inventor Productivity. Res. Policy. 36(5) 619-636.

Jaffe, A.B. , M. Trajtenberg.2002. Patents, Citations \& Innovations: A Window on the Knowledge Economy. MIT Press, Boston, MA.

Kogut, B., U. Zander. 1992. Knowledge of the Firm, Combinative Capabilities, and the Replication of Technology. Organ. Sci. 3(2) 383-397.

Kim, J., G. Marschke.2009. Research Scientist Productivity and Firm Size: Evidence from Panel Data on Inventors. Pacific Economic Review. 14(4) 516-531.

Lai, R., A. D'Amour, A. Yu, Y. Sun, V. Torvik, L. Fleming. 2009. Disambiguation and co-author networks of the U.S. Patent Inventor Database. Working paper, Harvard Business School, Cambridge, MA.

Lacetera, N. 2009. Different Missions and Commitment Power in R\&D Organization: Theory and Evidence on Industry-University Relations. Organ. Sci. 20 (3) 565-582.

Long, J.S. 1997. Regression Models for Categorical and Limited Dependent Variables. Sage Publications, Thousand Oaks, CA.

Mansfield, E. 1995. Academic Research Underlying Industrial Innovations: Sources, Characteristics, and Financing. The Review of Economics and Statistics. 77(1) 55-65.

Mansfield, E. 1998. Academic research and industrial innovation: An update of empirical findings. Res. Policy. 26(7-8) 773-776.

Merton, R. 1973. The Sociology of Science. Chicago University Press, Chicago, IL.

Meyer-Krahmer, F., U. Smoch. 1998. Science-based technologies: university-industry interactions in four fields. Res. Policy. 27(8) 835-851.

Mokyr, J. 2002. The Gifts of Athena: Historical Origins of the Knowledge Economy. Princeton University Press, Princeton, NJ.

Nelson, R. 1959. The Simple Economics of Basic Scientific Research. J. Political Econom. 67(3) 297-306.

OECD. 1994. The Measurement of Scientific and Technological Activities: Using Patent Data as Science and Technology Indicators, Patent Manual. OECD/GD(94)114, Paris.

OECD. 2002. Frascati manual: Proposed Standard Practice for Surveys on Research and Experimental Development.

Oettl, A., A. Agrawal. 2008. International Labor Mobility and Knowledge Flow Externalities. $J$. Internat. Bus. Stud. 39(8) 1242-1260.

Palomeras, N., E. Melero. 2010. Learning by Hiring as a Driver of Mobility. Management Sci. 56(5) 881-895.

Reitzig, M. 2004. Improving patent valuations for management purposes —validating new indicators by analyzing application rationales. Res. Policy. 33 939-957.

Rosenkopf, L., A. Nerkar. 2001. Beyond local search: boundary-spanning, exploration, and impact in 
the optical disk industry. Strategic Management J. 22(4) 287- 306.

Rosenkopf, L., P. Almeida. 2003. Overcoming local search through alliances and mobility. Management Sci. 49(6) 751-766.

Rysman, M., T. Simcoe. 2008. Patents and the Performance of Voluntary Standard-setting Organizations. Management Sci. 54(11) 1920-1934.

Scotchmer, S. 1991. Standing on the shoulders of giants: Cumulative research and the patent law. The Journal of economic Perspectives. 5(1) 29-41.

Singh, J. 2008. Distributed R\&D, Cross-Regional Knowledge Integration and Quality of Innovative Output. Res. Policy. 37(1) 77-96.

Singh, J., A. Agrawal. 2011. Recruiting for Ideas: How Firms Exploit the Prior Inventions of New Hires. Management Sci. 57(1) 129-150.

Song, J., P. Almeida P., G. Wu. 2003. Learning by hiring: When is mobility more to facilitate knowledge transfer? Management Sci. 49(4) 351-365.

Sørensen, J.B., T.E. Stuart. 2000. Aging, Obsolescence, and Organizational Innovation. Admin. Sci.Quart. 45(1) 81-112.

Stephan, P. 1996. The economics of science. J. Econom. Literature. 34 1199-1235.

Trajtenberg, M. 1990. A Penny for Your Quotes: Patent Citations and the Value of Innovations. RAND J. Econom. 21(1) 172-187.

Tushman, M., T. Scanlan. 1981.Boundary Spanning Individuals: Their Role in Information Transfer and Their Antecedents. Acad. Management J. 24( 2) 289-305.

Van Helleputte, J.C., A. Reid. 2004. Tackling the paradox: can attaining global research excellence be compatible with local technology development? R\&D Management. 34(1) 33-44.

Veugelers, R., B. Cassiman. 2005. R\&D Cooperation Between Firms and Universities: Some empirical evidence from Belgian manufacturing. International journal of Industrial Organization. 23(5-6) 355-379.

Ziedonis, A., R.H. Ziedonis. 2005. Research Consortia as Performers and Brokers of R\&D: Tradeoffs for Member Firms. Mimeo, Ross School of Management, Ann Arbor, MI.

Zucker, L.G., M.R. Darby, M.B. Brewer. 1998. Intellectual Capital and the Birth of U.S. Biotechnology Enterprises. Amer. Econom. Rev. 88(1) 290-306.

Zucker, L.G., M.R. Darby. 2001. Capturing Technological Opportunity via Japan's Star Scientists: Evidence from Japanese Firms' Biotech Patents and Products. The Journal of Technology Transfer. 26(1-2) 37-58.

Zucker, L.G., M.R. Darby, J.S. Armstrong. 2002. Commercializing Knowledge: University Science, Knowledge Capture, and Firm Performance in Biotechnology. Management Sci. 48(1) 138153. 
Table 1: Patent Types

IMEC Partner

Yes

Boundary-Crossing Inventor

No

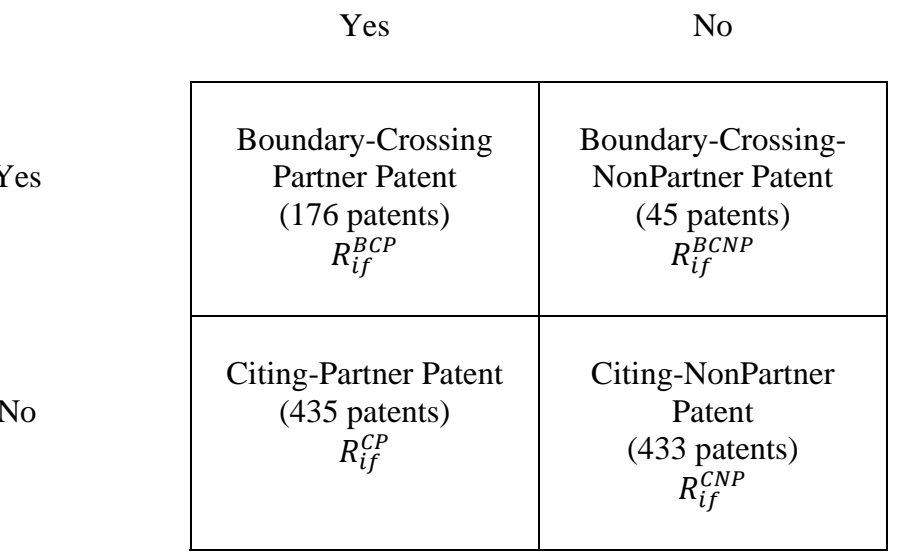

Table 2: Descriptive Statistics

\begin{tabular}{|c|c|c|c|c|c|c|}
\hline & Description Variables & Obs & Mean & Std Dv & Min & Max \\
\hline Count forward citations & $\begin{array}{l}\text { The number of times a patent is cited as } \\
\text { prior art by subsequent patents }\end{array}$ & 1089 & 5.31 & 11.01 & 0 & 131 \\
\hline Count forward citations within 3 years & $\begin{array}{l}\text { The number of times a patent is cited as } \\
\text { prior art by subsequent patents within } \\
\text { three years after application }\end{array}$ & 1089 & 2.87 & 5.17 & 0 & 61 \\
\hline Forward citations binary & $\begin{array}{l}\text { Dummy indicating whether a patent } \\
\text { received citation(s) }\end{array}$ & 1089 & 0.69 & 0.46 & 0 & 1 \\
\hline Count forward self citations & $\begin{array}{l}\text { The number of times a patent is cited by } \\
\text { patents assigned to the same company }\end{array}$ & 1089 & 1.31 & 5.49 & 0 & 116 \\
\hline Count forward self citations within $\mathbf{3}$ years & $\begin{array}{l}\text { The number of times a patent is cited by } \\
\text { patents of the same company within three } \\
\text { years after application }\end{array}$ & 1089 & 0.81 & 2.23 & 0 & 27 \\
\hline Proportion forward self citations & $\begin{array}{l}\text { The number of self citations divided by } \\
\text { total amount of forward citations }\end{array}$ & 1089 & 0.17 & 0.31 & 0 & 1 \\
\hline Forward self citations binary & $\begin{array}{l}\text { Dummy indicating whether a patent } \\
\text { received self citation }(s)\end{array}$ & 1089 & 0.32 & 0.47 & 0 & 1 \\
\hline Patent scope (Count IPCs) & The number of IPC codes & 1089 & 2.58 & 2.07 & 1 & 14 \\
\hline Count non-patent references (NPRS) & $\begin{array}{l}\text { The number of ISI web of knowledge } \\
\text { scientific publications cited }\end{array}$ & 1089 & 7.76 & 15.53 & 0 & 99 \\
\hline Count patent references (PRS) & The number of patents cited by the patent & 1089 & 30.41 & 31.43 & 0 & 147 \\
\hline Count inventors & The number of inventors on the patent & 1089 & 2.94 & 2.10 & 1 & 15 \\
\hline Inventor experience & $\begin{array}{l}\text { The number of patents (in ' } 000 \text { ) applied } \\
\text { for by the inventors before the application }\end{array}$ & 1089 & 0.07 & 0.15 & 0 & 2 \\
\hline Scale & $\begin{array}{l}\text { The number of patents (in '000) the } \\
\text { applicant company applied for in the last } 5 \\
\text { years before the application }\end{array}$ & 1089 & 4.25 & 4.39 & 0 & 20 \\
\hline Scope & $\begin{array}{l}\text { The number of unique IPC codes (in '000) } \\
\text { appearing on the company's patents } \\
\text { applied for in the last } 5 \text { years before the } \\
\text { application }\end{array}$ & 1089 & 1.27 & 1.16 & 0 & 5 \\
\hline Age company & $\begin{array}{l}\text { The number of years since the company's } \\
\text { first patent }\end{array}$ & 1089 & 50.92 & 28.19 & 4 & 109 \\
\hline
\end{tabular}


TABLE 3: Descriptive Statistics (Average) by Patent Type

\begin{tabular}{|c|c|c|c|c|c|}
\hline & \multirow[t]{2}{*}{$\begin{array}{c}\text { IMEC } \\
\text { patents }\end{array}$} & \multicolumn{2}{|c|}{$\begin{array}{c}\text { IMEC PARTNER } \\
\text { patents }\end{array}$} & \multicolumn{2}{|c|}{$\begin{array}{c}\text { NOT IMEC-PARTNER } \\
\text { patents }\end{array}$} \\
\hline & & $\begin{array}{l}\text { BOUNDARY } \\
\text { CROSSING } \\
\text { INVENTOR }\end{array}$ & CITING & $\begin{array}{l}\text { BOUNDARY } \\
\text { CROSSING } \\
\text { INVENTOR }\end{array}$ & CITING \\
\hline Count forward citations & 7.38 & 7.32 & 4.40 & 5.80 & 5.48 \\
\hline Count forward citations within $3 \mathrm{y}$ & 3.25 & 4.42 & 2.38 & 1.69 & 2.86 \\
\hline Forward citations binary & 0.76 & 0.64 & 0.66 & 0.56 & 0.76 \\
\hline Count forward self citations & 0.79 & 2.50 & 1.40 & 0.31 & 0.87 \\
\hline Count forward self citations within $3 \mathrm{y}$ & 0.35 & 1.21 & 0.90 & 0.11 & 0.61 \\
\hline Proportion forward self citations & 0.13 & 0.20 & 0.20 & 0.06 & 0.13 \\
\hline Forward self citations binary & 0.29 & 0.34 & 0.35 & 0.17 & 0.31 \\
\hline Non-Patent Reference binary & 0.81 & 0.60 & 0.60 & 0.47 & 0.65 \\
\hline Number of Observations & 255 & 176 & 435 & 45 & 433 \\
\hline
\end{tabular}


Table 4: Count Forward Patent Citations

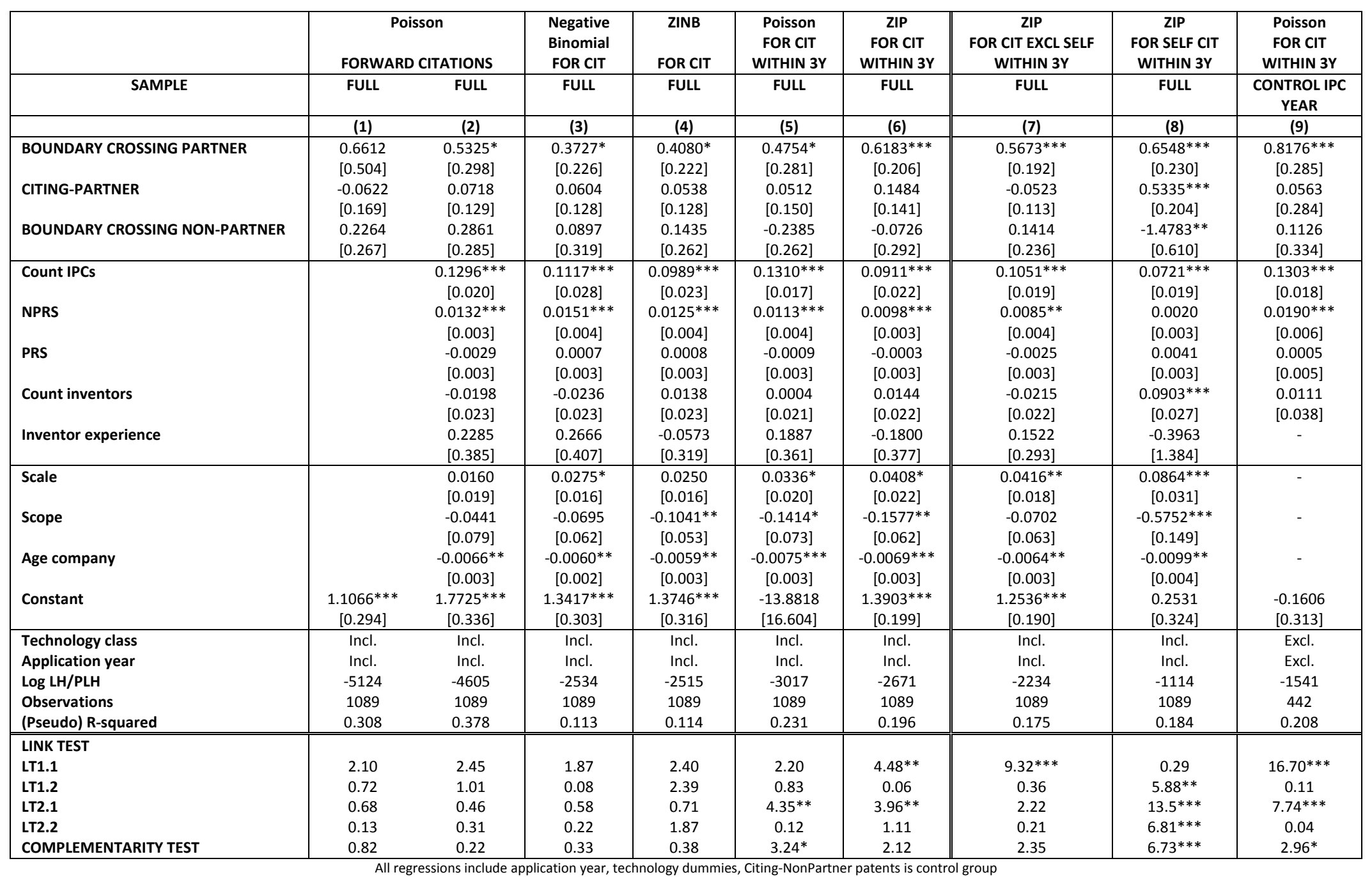

Robust standard errors in brackets, clustered by firm, application year and technology class dummies are used to model the variance term in the negative binomial model ${ }^{* * *} \mathrm{p}<0.01, * * \mathrm{p}<0.05, * \mathrm{p}<0.1$

Marginal Effects (3): Crossing-Partner 70\%*; Citing-Partner 7\%; Crossing-NonPartner 33\% 
Table5: Proportion Self-citations

\begin{tabular}{|c|c|c|c|c|c|}
\hline \multirow[b]{2}{*}{ SAMPLE } & \multicolumn{2}{|c|}{ OLS } & \multicolumn{2}{|c|}{ HETORSKEDASTIC TOBIT } & \multirow{2}{*}{$\begin{array}{c}\text { TOBIT } \\
\text { CONTROL IPC YEAR } \\
\text { (5) }\end{array}$} \\
\hline & $\begin{array}{l}\text { FULL } \\
\text { (1) }\end{array}$ & $\begin{array}{l}\text { FULL } \\
\text { (2) }\end{array}$ & $\begin{array}{l}\text { FULL } \\
\text { (3) }\end{array}$ & $\begin{array}{l}\text { FULL } \\
\text { (4) }\end{array}$ & \\
\hline BOUNDARY CROSSING PARTNER & $\begin{array}{c}0.0784^{* *} \\
{[0.031]}\end{array}$ & $\begin{array}{c}0.1050^{* * *} \\
{[0.026]}\end{array}$ & $\begin{array}{l}0.2184^{*} \\
{[0.118]}\end{array}$ & $\begin{array}{c}0.3297^{* * *} \\
{[0.089]}\end{array}$ & $\begin{array}{c}0.5348^{* *} \\
{[0.258]}\end{array}$ \\
\hline CITING PARTNER & $\begin{array}{c}0.0666^{*} \\
{[0.039]}\end{array}$ & $\begin{array}{l}0.0680^{*} \\
{[0.039]}\end{array}$ & $\begin{array}{l}0.1672 \\
{[0.125]}\end{array}$ & $\begin{array}{c}0.2071^{*} \\
{[0.108]}\end{array}$ & $\begin{array}{c}0.6770 * * * \\
{[0.254]}\end{array}$ \\
\hline BOUNDARY CROSSING NON-PARTNER & $\begin{array}{c}-0.0566^{*} \\
{[0.034]} \\
\end{array}$ & $\begin{array}{l}-0.0358 \\
{[0.038]} \\
\end{array}$ & $\begin{array}{c}-0.5689 * * * \\
{[0.202]} \\
\end{array}$ & $\begin{array}{c}-0.4487^{* *} \\
{[0.197]} \\
\end{array}$ & $\begin{array}{l}-0.2564 \\
{[0.337]} \\
\end{array}$ \\
\hline Count IPCs & & $\begin{array}{l}0.0013 \\
{[0.005]}\end{array}$ & & $\begin{array}{l}0.0091 \\
{[0.014]}\end{array}$ & $\begin{array}{l}-0.0024 \\
{[0.021]}\end{array}$ \\
\hline NPRS & & $\begin{array}{l}0.0010 \\
{[0.001]}\end{array}$ & & $\begin{array}{l}0.0033 \\
{[0.003]}\end{array}$ & $\begin{array}{l}0.0047 \\
{[0.006]}\end{array}$ \\
\hline PRS & & $\begin{array}{c}0.0014^{* *} \\
{[0.001]}\end{array}$ & & $\begin{array}{c}0.0051^{* * *} \\
{[0.002]}\end{array}$ & $\begin{array}{l}-0.0014 \\
{[0.004]}\end{array}$ \\
\hline Count inventors & & $\begin{array}{l}-0.0033 \\
{[0.005]}\end{array}$ & & $\begin{array}{l}0.0014 \\
{[0.016]}\end{array}$ & $\begin{array}{l}-0.0098 \\
{[0.029]}\end{array}$ \\
\hline Count for citations & $\begin{array}{c}0.0029 * * * \\
{[0.001]}\end{array}$ & $\begin{array}{c}0.0023 * * * \\
{[0.001]}\end{array}$ & $\begin{array}{c}0.0148^{* * *} \\
{[0.004]} \\
\end{array}$ & $\begin{array}{c}0.0114^{* * *} \\
{[0.004]}\end{array}$ & $\begin{array}{c}0.0223^{* * *} \\
{[0.005]}\end{array}$ \\
\hline Inventor experience & & $\begin{array}{l}-0.0197 \\
{[0.129]} \\
\end{array}$ & & $\begin{array}{l}-0.1439 \\
{[0.548]} \\
\end{array}$ & - \\
\hline Scale & & $\begin{array}{l}0.0044 \\
{[0.004]}\end{array}$ & & $\begin{array}{l}0.0127 \\
{[0.021]}\end{array}$ & - \\
\hline Scope & & $\begin{array}{c}-0.0252^{*} \\
{[0.015]}\end{array}$ & & $\begin{array}{c}-0.1181^{*} \\
{[0.066]}\end{array}$ & - \\
\hline Age company & & $\begin{array}{l}-0.0001 \\
{[0.000]} \\
\end{array}$ & & $\begin{array}{r}-0.0011 \\
{[0.002]} \\
\end{array}$ & - \\
\hline Constant & $\begin{array}{l}-0.0019 \\
{[0.044]} \\
\end{array}$ & $\begin{array}{l}0.0121 \\
{[0.062]}\end{array}$ & $\begin{array}{c}-0.3158^{*} \\
{[0.164]} \\
\end{array}$ & $\begin{array}{c}-0.4811^{* * *} \\
{[0.138]}\end{array}$ & $\begin{array}{c}-1.1235^{* * *} \\
{[0.275]}\end{array}$ \\
\hline Technology class & Incl. & Incl. & Incl. & Incl. & Excl. \\
\hline Application year & Incl. & Incl. & Incl. & Incl. & Excl. \\
\hline $\begin{array}{l}\text { Censoring (at } 0 \text { or } 1 \text { ) } \\
\text { Heteroskedasticity test }\end{array}$ & & & $\begin{array}{c}75 \% \\
8.34^{*}\end{array}$ & $\begin{array}{c}75 \% \\
18.04^{* * *}\end{array}$ & $78 \%$ \\
\hline Log PLH & & & -752.9022 & -727.8352 & -331.07743 \\
\hline Observations & 1089 & 1089 & 1089 & 1089 & 442 \\
\hline $\begin{array}{l}\text { (Pseudo) R-squared } \\
\text { LINK TEST }\end{array}$ & 0.097 & 0.130 & 0.113 & 0.142 & 0.058 \\
\hline $\begin{array}{l}\text { LINK TEST } \\
\text { LT1.1 }\end{array}$ & 0.09 & 0.76 & 0.18 & 0.92 & 0.84 \\
\hline LT1.2 & $2.80^{*}$ & 0.90 & $7.93^{* * *}$ & $5.19 * *$ & 0.58 \\
\hline LT2.1 & $12.94^{* * *}$ & $13.11^{* * *}$ & $15.11^{* * *}$ & $14.30^{* * *}$ & $7.87^{* * *}$ \\
\hline LT2.2 & $2.91 *$ & $2.98^{*}$ & 1.78 & $3.71^{*}$ & $7.13^{* * *}$ \\
\hline COMPLEMENTARITY TEST & 1.75 & 1.67 & $8.31^{* * *}$ & $6.46^{* *}$ & 0.10 \\
\hline
\end{tabular}

All regressions include application year and technology dummies, Citing-NonPartner patents is control group

Robust standard errors in brackets, clustered by firm, heteroskedasticity term includes 4 scale class dummies ${ }^{* * *} p<0.01,{ }^{* *} p<0.05,{ }^{*} p<0.1$

Marginal Effects (6): Crossing-Partner $0.065^{* * *}$, Citing-Partner0.032***, CitingNonPartner $-0.033^{* *}$ 
Table 6: Robustness Sample Selection

\begin{tabular}{|l|c|c||c|c||c|c|}
\hline & \multicolumn{3}{|c||}{ IMEC PARTNER } & \multicolumn{3}{c||}{ NOT IMEC-PARTNER } \\
\hline & $\begin{array}{c}\text { BOUNDARY } \\
\text { CROSSING } \\
\text { INVENTOR }\end{array}$ & $\begin{array}{c}\text { BOUNDARY } \\
\text { CROSSING } \\
\text { INVENTOR } \\
\text { CITING }\end{array}$ & CITING & $\begin{array}{c}\text { BOUNDARY } \\
\text { CONTROL } \\
\text { IPC-YEAR } \\
\text { CROSSING } \\
\text { INVENTOR }\end{array}$ & $\begin{array}{c}\text { BOUNDARY } \\
\text { CROSSING } \\
\text { INVENTOR } \\
\text { CITING }\end{array}$ & $\begin{array}{c}\text { CITING } \\
\text { CONTROL } \\
\text { IPC-YEAR }\end{array}$ \\
\hline $\begin{array}{l}\text { Count forward } \\
\text { citations }\end{array}$ & 7.32 & 4.92 & 4.40 & 2.99 & 5.80 & 2.44 \\
\hline $\begin{array}{l}\text { Count forward } \\
\text { citations within 3 y }\end{array}$ & 4.42 & 4.25 & 2.38 & 2.15 & 1.69 & 1.44 \\
\hline $\begin{array}{l}\text { Proportion forward } \\
\text { self citations }\end{array}$ & 0.20 & 0.36 & 0.20 & 0.20 & 0.06 & 2.86 \\
\hline $\begin{array}{l}\text { Number } \\
\text { Observations of }\end{array}$ & 164 & 12 & 433 & 176 & 36 & 0.00 \\
\hline
\end{tabular}

Table 7: Matched Partner/Non-Partner Patents

\begin{tabular}{|c|c|c|c|c|}
\hline \multicolumn{5}{|c|}{ BOUNDARY CROSSING PARTNER VS CITING NON-PARTNER } \\
\hline & $\begin{array}{l}\text { PARTNER } \\
\text { (TREATED) }\end{array}$ & $\begin{array}{l}\text { NON-PARTNER } \\
\text { (NON-TREATED) }\end{array}$ & $\mathrm{t}$ & $\begin{array}{l}\text { TTEST } \\
\mathrm{P}>|\mathrm{t}|\end{array}$ \\
\hline Count forward cit 3y & 4.57 & 1.40 & 4.25 & 0.00 \\
\hline Proportion self citations & 0.21 & 0.04 & 5.99 & 0.00 \\
\hline \multicolumn{5}{|c|}{ CITING PARTNER vs CITING NON-PARTNER (LT2.2) } \\
\hline & $\begin{array}{l}\text { PARTNER } \\
\text { (TREATED) }\end{array}$ & $\begin{array}{l}\text { NON-PARTNER } \\
\text { (NON-TREATED) }\end{array}$ & $\mathbf{t}$ & $\begin{array}{l}\text { TTEST } \\
\mathrm{P}>|\mathrm{t}|\end{array}$ \\
\hline Count forward cit 3y & 2.47 & 2.49 & -0.07 & 0.94 \\
\hline Proportion self citations & 0.20 & 0.07 & 6.74 & 0.00 \\
\hline \multicolumn{5}{|c|}{ BOUNDARY CROSSING PARTNER VS BOUNDARY CROSSING NON-PARTNER (LT2.1) } \\
\hline & $\begin{array}{l}\text { PARTNER } \\
\text { (TREATED) } \\
\end{array}$ & $\begin{array}{c}\text { NON-PARTNER } \\
\text { (NON-TREATED) }\end{array}$ & $\mathbf{t}$ & $\begin{array}{l}\text { TTEST } \\
P>|t|\end{array}$ \\
\hline Count forward cit 3y & 5.39 & 1.69 & 3.91 & 0.00 \\
\hline Proportion self citations & 0.24 & 0.18 & 1.73 & 0.09 \\
\hline
\end{tabular}

Averages do not necessarily match the descriptives of Table 3 as only successfully matched patents within the common support are used in the calculation of the averages. 
APPENDIX: Partner Patent Selection Equation

\begin{tabular}{|c|c|}
\hline VARIABLES & Partner Dummy Patent \\
\hline \multicolumn{2}{|l|}{$\begin{array}{l}\text { PATENT CHARACTERISTICS } \\
\end{array}$} \\
\hline Count IPCs & $\begin{array}{c}-0.0760 * * \\
{[0.0297]}\end{array}$ \\
\hline NPRS & $\begin{array}{l}-0.0107 * \\
{[0.0064]}\end{array}$ \\
\hline PRS & $\begin{array}{c}0.0038 \\
{[0.0038]}\end{array}$ \\
\hline Count inventors & $\begin{array}{c}0.0511 \\
{[0.0329]}\end{array}$ \\
\hline \multicolumn{2}{|l|}{ FIRM CORE TECHNOLOGY } \\
\hline Electrical machinery and apparatus, electrical energy & $\begin{array}{c}-0.9625 \\
{[0.9643]}\end{array}$ \\
\hline Audio-visual technology & $\begin{array}{c}0.7735 \\
{[0.8911]}\end{array}$ \\
\hline Telecommunications & $\begin{array}{c}-1.5170 * * \\
{[0.6508]}\end{array}$ \\
\hline Information technology & $\begin{array}{c}0.5640 \\
{[0.6704]}\end{array}$ \\
\hline Semiconductors & $\begin{array}{c}1.9357^{* * *} \\
{[0.5286]}\end{array}$ \\
\hline Optics & $\begin{array}{l}1.6428^{*} \\
{[0.8448]}\end{array}$ \\
\hline Analysis, measurement, control technology & $\begin{array}{c}0.7639 \\
{[0.8669]}\end{array}$ \\
\hline Chemical engineering & $\begin{array}{c}2.2081^{* *} \\
{[0.9916]}\end{array}$ \\
\hline \multicolumn{2}{|l|}{ HEADQUARTERS } \\
\hline US & $\begin{array}{c}0.7623 \\
{[0.7775]}\end{array}$ \\
\hline EU & $\begin{array}{c}3.3017^{* * *} \\
{[0.9592]}\end{array}$ \\
\hline Japan & $\begin{array}{c}-0.4943 \\
{[0.8549]} \\
\end{array}$ \\
\hline \multicolumn{2}{|l|}{ FIRM CHARACTERISTICS } \\
\hline Top 25 firm in sales & $\begin{array}{l}1.3454^{* *} \\
{[0.5343]}\end{array}$ \\
\hline Scale & $\begin{array}{l}-0.0989 \\
{[0.0915]}\end{array}$ \\
\hline Scope & $\begin{array}{c}0.4698 \\
{[0.3572]}\end{array}$ \\
\hline Age & $\begin{array}{c}0.0052 \\
{[0.0096]}\end{array}$ \\
\hline Constant & $\begin{array}{c}-2.8132 * * * \\
{[0.8811]}\end{array}$ \\
\hline Observations & 1089 \\
\hline Pseudo R-squared & 0.446 \\
\hline$\%$ correctly estimated & $82 \%$ \\
\hline
\end{tabular}

